\title{
O papel do controle interno na gestão municipal
}

\author{
José Saraiva dos Santos ${ }^{1}$ \\ Isac Candido da Silva ${ }^{2}$ \\ ${ }^{1}$ Universidade Estadual de Alagoas - UNEAL. Mestrando em Dinâmicas Territoriais e Cultura. \\ e-mail: jose.saraiva.santos@hotmail.com \\ ${ }^{2}$ Universidade Estadual de Alagoas - UNEAL.Especialista em Gestão Pulica. \\ e-mail: isac.candido@hotmail.com
}

\begin{abstract}
Resumo - O presente estudo aborda a temática do controle interno como instrumento de gestão na Administração Pública Municipal, tendo como objetivo geral verificar quais devem ser os mecanismos de controle adotados em uma administração municipal, observando a importância e limitações no processo de gestão. Objetivou-se identificar como é feito o controle interno na gestão municipal, discutir qual a real necessidade da implantação do Sistema de Controle Interno, evidenciar o Controle Interno como instrumento de gestão, e eficiência dos gastos públicos. Para obtenção de tais resultados, foi realizada uma abordagem da Administração Pública e Controle Interno, citando aspectos cronológicos, histórico, os tipos de controle, bem como os princípios que norteiam o controle, adentrando na sequência ao Sistema de Controle Interno. A partir de uma pesquisa bibliográfica, todo material didático pesquisado inferiu-se que, o controle interno bem aplicado, através do Sistema de Controle Interno, auxilia o processo de fiscalização da gestão municipal, constituindo-se em um instrumento de apoio aos gestores para se buscar a melhoria da qualidade dos serviços prestados e contribuir para uma gestão pública mais eficiente.
\end{abstract}

Palavras-chave: Administração Pública, Controle Interno, Sistema de Controle Interno Municipal.

\begin{abstract}
This study addresses the issue of internal control as a management tool in the Municipal Public Administration, with the general objective of verifying which control mechanisms should be adopted in a municipal administration, observing the importance and limitations in the management process. The objective was to identify how internal control is carried out in municipal management, to discuss the real need for the implementation of the Internal Control System, to highlight Internal Control as a management tool, and the efficiency of public spending. To obtain such results, an approach of Public Administration and Internal Control was carried out, citing chronological aspects, history, types of control, as well as the principles that guide control, entering the Internal Control System in sequence. From a bibliographic research, all didactic material researched it was inferred that, the internal control well applied, through the Internal Control System, helps the process of inspection of the municipal management, constituting an instrument of support to the managers to seek to improve the quality of services provided and contribute to more efficient public management.
\end{abstract}

Keywords: Public Administration, Internal Control, Municipal Internal Control System. 


\section{Introdução}

Com o atual cenário social e econômico brasileiro exige cada vez mais dos órgãos da Administração Governamental transparência com relação à utilização dos recursos públicos oriundos de tributos que são pagos por cada cidadão. Neste sentido surge a necessidade de que os órgãos públicos invistam em sistemas de controle interno para que se possa obter uma melhor utilização de recursos com vista à eficiência e racionalidade.

A lei $\mathrm{n}^{\circ}$ 101, de 04 de maio de 2000, denominada de Lei de Responsabilidade Fiscal - RLF traz normas de finanças públicas voltadas para a responsabilidade na gestão fiscal, a fim de coibir a corrupção e controlar melhor as finanças destinadas aos órgãos da administração pública. A citada lei cobra maior responsabilidade fiscal e também fixa normas para aplicabilidade de ações que devem ser realizadas de forma planejada e transparente, minimizando riscos e desvios que possam colocar as finanças públicas em desequilíbrio, ou seja, essa dispõe sobre um novo padrão de governar, com foco em limites e responsabilidades, vinculando o dever da prestação de contas para a população contribuinte à política fiscal no Brasil.

A institucionalização e implementação do Sistema de Controle Interno não é somente uma exigência das Constituições Federal, Estadual e da Lei de Responsabilidade Fiscal, mas também uma ótima oportunidade para dotar os órgãos governamentais de mecanismos que assegurem, entre outros aspectos, o cumprimento às exigências legais, a proteção de seu patrimônio e a otimização na aplicação dos recursos públicos, garantindo maior segurança aos seus gestores.

Atualmente, a perspectiva é de que o sistema de controle interno seja um instrumento essencial da gestão para propiciar uma razoável margem de garantia de que os objetivos e metas da entidade serão atingidos de maneira eficaz, eficiente e com a necessária economicidade.

Considerando que a necessidade de estabelecer prioridades, objetivos e metas, expressos em instrumentos de planejamento e gestão, tais como o Plano Plurianual - PPA, a Lei das Diretrizes Orçamentárias - LDO e a Lei Orçamentária Anual - LOA. Ocorre que diante destas circunstâncias para que os resultados possam ser alcançados com êxito, faz-se necessária também à adoção de medidas que possibilitem a gestão desses recursos de forma eficiente e em consonância com a Lei de Responsabilidade Fiscal e demais legislações pertinentes ao assunto. Neste sentido, surge a necessidade de implantar e operacionalizar um Sistema de Controle Interno. Portanto, nesta linha de 
pensamento este trabalho discorrerá sobre o seguinte problema: Como o Controle Interno pode contribuir para uma gestão municipal eficiente?

Baseado em pesquisa bibliográfica e dentro dos preceitos da Constituição Federal e outras fontes relacionadas aos atos da Administração Pública, fica evidenciado o que realmente representa Controle Interno. Com o conteúdo abordado, espera-se que este trabalho se torne fonte de pesquisa para alunos, professores e gestores públicos, a fim de que haja uma maior compreensão e implementação do controle interno como instrumento de gestão, equilíbrio fiscal e eficiência dos gastos públicos.

\section{Conceito de Administração Pública}

A Administração pública é um sistema complexo, composto de instituições e órgãos do Estado, normas, recursos humanos, infraestrutura, tecnologia, cultura, entre outras, encarregada de exercer de forma adequada a autoridade política e as suas demais funções constitucionais, com o objetivo de atingir o bem comum (Matias-Pereira, 2012).Ao tratar sobre o conceito de Administração pública Silva (2001, citado por CASTRO 2013, p. 18) afirma que:

Administração pública é o conjunto de meios institucionais, materiais, financeiros e humanos organizados e necessários para executar as decisões políticas. Representa o conjunto de órgãos utilizados pelo poder político para atingir fins definidos.

A Administração Pública Federal foi definida pelo Decreto-Lei 200/67, que a dividiu em duas áreas: Administração Direta e Administração Indireta. A Administração Direta abrange os três poderes (executivo, legislativo e judiciário) e compreende o conjunto de órgãos integrados, responsáveis pela condução da administração da União, como são os ministérios. A administração Indireta compõe-se do conjunto de entes vinculados a cada Ministério: autarquias, empresas públicas ou estatais, fundações públicas e Sociedades de economia mista (CASTRO, 2013).Da mesma forma, também ocorre à estruturação da Administração Pública nos Estados, Distrito Federal e municípios.

\section{Conceito de Controle}

Segundo Castro (2013, p. 323): 
Historicamente, a palavra controle sempre esteve ligado a finanças. Em francês, contrôler significa registrar, inspecionar, examinar. A palavra é originária de contre-rôler, registro efetuado em confronto com o documento original, com a finalidade da verificação da fidedignidade dos dados. Para o direito inglês, significa vigilância no italiano, controllo é o mesmo que registro ou exame. Consagrou-se o vocábulo, na técnica comercial, para indicar inspeção ou exame que se processa nos papéis ou nas operações registradas nos estabelecimentos comerciais.

De acordo com Fayol (aput ANTUNES, 1998, P. 61): “o controle consiste em verificar se tudo ocorre em conformidade com o plano adotado, as instruções emitidas e os princípios estabelecidos. Tem por objetivo apontar as falhas e os erros para retificá-los e evitar a sua reincidência. Aplica-se a tudo: coisas, pessoas, atos".

Conforme Meirelles (aput CASTRO, 2013, P. 324), “controle, na administração pública, é a faculdade de vigilância, orientação e correção que um Poder, Órgão ou Autoridade exerce sobre a conduta funcional de outro".

\section{Tipos de Controle}

O Controle pode ser interno ou externo. O controle externo é exercido pelos tribunais de contas, poder legislativo, judiciário, pela população (Controle social) e controle pelos conselhos fiscais. No entanto, neste trabalho será abordado o controle interno no âmbito municipal.

\section{Controle Interno}

Para conceituar Controle Interno vamos iniciar com uma definição encontrada no Guia de Orientação para Implantação do Sistema de Controle Interno na Administração Pública do Tribunal de Contas do Estado do Espírito Santo:

Controle é toda atividade de verificação sistemática de um registro, exercida de forma permanente ou periódica, consubstanciada em documento ou outro meio, que expresse uma ação, uma situação e/ou um resultado, com o objetivo de verificar se está em conformidade com o padrão estabelecido, ou com o resultado esperado, ou, ainda, com o que determinam a legislação e as normas.

De acordo com Cavalheiro e Flores (2007, pg.27) "Controlar significa comparar o que foi feito com um padrão, com o que deveria ser feito. É um espelho, um parâmetro.”.Os autores também relatam que: 
Os controles internos servem para auxiliar o gestor na busca de sua missão - colocar serviços públicos à disposição da comunidade -, tendo em vista a necessidade de conhecimento daquilo que ocorre no Município, não com conhecimento empírico (baseado somente na experiência - quando existe - e sem nenhum conhecimento científico), mas, sim, voltado para técnicas modernas de administração (planejamento e gestão). Antes de serem meio de fiscalização, os controles internos têm cunho preventivo, pois oferecem ao gestor público a tranquilidade de estar informado da legalidade dos atos de administração que estão sendo praticados, da viabilidade ou não do cumprimento das diretrizes e metas estabelecidas, possibilitando a correção de desvios ou rumos da sua administração. Em síntese, os controles internos dão a possibilidade de exercer, realmente, a função de "gestor dos negócios públicos".

\section{Plano básico de organização de um sistema de controle interno}

O plano de organização reflete na maneira como o sistema de controle deve ser organizado, pois o mesmo deve estabelecer a divisão das tarefas a serem executadas entre os órgãos e pessoas da entidade e definir as relações de autoridades e competências de cada um, sempre visando à missão da organização. Ressaltando que, cada sistema deve ser elaborado levando em consideração a atividade desempenhada pela sua entidade como também deve ser planejado levando em conta a praticidade a economicidade a eficiência e a eficácia, sempre buscando galgar o sucesso no planejamento do sistema de controle.

Por motivo do artigo 31 da Carta Magna, a implementação do Sistema de Controle Interno no município, deve ser mediante lei de iniciativa do Poder executivo. Dessa forma, é indispensável que a lei que instituiu o Sistema de Controle Interno, regule a forma de controle a ser realizado. Deve o Sistema de Controle Interno ser executado dentro da própria organização controlada, por meio de procedimentos e atividades intersetoriais, com vistas à realização eficiente do sistema e a correta gestão dos bens públicos.

Percebe-se a importância que cabe a cada setor que compõe a Administração Pública no que tange ao conhecimento do funcionamento, da legalidade e da responsabilidade do responsável pelo Sistema de Controle Interno, não desprezando a importância de repassar para o responsável pelo controle interno, informações corretas e em tempo hábil.Em relação a atuação do pessoal envolvido, Gattringer ( 2006. p.104) descreve:

$\{\ldots$... o sistema de controle interno se operacionaliza através de um órgão ou unidade central que, além de coordenar e avaliar o sistema, também detém a finalidade de efetuar a centralização das ações, recolhendo as informações dos demais órgãos que executam as ações propriamente ditas, certificando-se de que cada ato administrativo gerado foi 
desenvolvido pelo setor e funcionário que detinha a devida competência, e na forma dos regulamentos estabelecidos.

Depois da criação da LRF é imprescindível a implantação de um Sistema de Controle Interno, pois o mesmo servirá como ferramenta para gerir melhor os recursos, dirimindo qualquer dúvida sobre sua aplicabilidade. A implantação de um sistema facilita a fiscalização e atuação, responsabilizando o gestor público quando este não lhe assegura as condições para o cumprimento do mandamento constitucional.

\section{Auditoria}

As atividades inerentes ao Sistema de Controle Interno são desenvolvidas mediante a utilização de técnicas próprias de trabalho, as quais se constituem num conjunto de procedimentos que proporcionam o alcance dos objetivos e metas do sistema. Para que tenhamos uma maior compreensão sobre o assunto vamos discorrer abaixo sobre Auditoria.Na concepção de Chaves (2009, p.18) auditoria pode ser definida da seguinte forma:

É o conjunto de técnicas que visa avaliar a gestão pública, pelos processos e resultados gerenciais, e a aplicação de recursos públicos por entidades de direito público e privado, mediante a confrontação entre uma situação encontrada com um determinado critério técnico, operacional ou legal. Trata-se de um importante instrumento de controle do Estado na busca da melhor alocação de seus recursos, não só atuando para corrigir os desperdícios, a improbidade, a negligência e a omissão e, principalmente, antecipando-se a essas ocorrências, buscando garantir os resultados pretendidos, além de destacar os impactos e benefícios sociais advindos.

Neste contexto, a aplicação das técnicas de auditoria se torna um importante instrumento a ser utilizado pelo administrador governamental na busca de melhores resultados com vista à otimização dos gastos públicos para um maior proveito da coletividade. A finalidade da auditoria de acordo com o Manual de Controle Interno da Controladoria Geral da União - CGU (BRASIL, 2007) é a de comprovar a legalidade e legitimidade dos atos e fatos administrativos e avaliar os resultados alcançados, quanto aos aspectos de eficiência, eficácia e economicidade da gestão orçamentária, financeira, patrimonial, operacional, contábil e finalística das unidades e das entidades da administração pública, em todas as suas esferas de governo e níveis de poder, bem como a aplicação de recursos públicos por entidades de direito privado, quando legalmente autorizadas nesse sentido. 
A Instrução Normativa - IN 1/2001 do Tribunal de Contas da União traz os seguintes tipos de auditoria: avaliação da gestão; de acompanhamento da gestão; contábil; operacional e especial.

A auditoria de gestão tem como objetivo emitir opinião com vistas a verificar a regularidade das contas, a execução dos programas de governo quanto à economicidade, eficiência e eficácia, a probidade na aplicação de dinheiros públicos e na guarda ou administração de valores e outros bens da União, verificar se há legalidade na atuação administrativa e a eficiência dos sistemas de controle administrativo e contábil (CASTRO, 2013).

A auditoria de acompanhamento da gestão é realizada anterior à auditoria de gestão. Devendo acontecer no decorrer do exercício, tem como objetivo principal, evidenciar melhorias e economias no processo, antecipando-se as ocorrências, evitando maiores transtornos (CASTRO, 2013).Em relação à auditoria contábil Cavalheiro e Flores (2007, pg.62) afirma o seguinte:

O contador não precisa ser o coordenador da equipe de controle interno, porém as tarefas de auditoria, verificação de demonstrações contábeis ou contas e outras correlatas (DecretoLei $\mathrm{n}^{\circ}$ 9.295--46, art. 25, art. 25, "c" e art. 261) devem ser afetas a ele, sob pena de exercício ilegal da profissão contábil, pois a auditoria contábil é prerrogativa dos bacharéis em Ciências Contábeis regularmente inscritos no respectivo CRC.

Por sua vez a auditoria operacional ou de desempenho consiste na realização de revisões de programas, organizações, atividades ou segmentos dos setores público e privado, com o objetivo de examinar e avaliar se os recursos da entidade ou órgão estão sendo aplicados com eficiência, como também se estão sendo alcançados os objetivos operacionais. Em outras palavras, a auditoria operacional pode ser compreendida como um processo de avaliação do desempenho, em confronto com o resultado esperado, consequentemente levando a emissão de relatórios com recomendações que devem ser utilizadas para melhoraria do desempenho da organização, Haller (1985, apud Araújo, 2006, p.29).No entendimento de Salomão (1999, pg.35):

\footnotetext{
No fundo pretende saber como o Governo adquire, protege e utiliza os seus recursos, quais as causas das práticas antieconômicas e ineficientes. Isto é, não apenas detectar problemas que geram a não economicidade e a ineficiência, mas também identificar as causas que provocam essas práticas, o cumprimento ou não das metas previstas, a observância das normas legais sobre economicidade, eficiência e eficácia da gestão, vale dizer a própria legalidade.
}

$\mathrm{Na}$ administração governamental, a auditoria operacional, preocupa-se com o exame independente e sucinto dos quatro "Es" (economicidade, eficiência, eficácia e efetividade) em relação ao objeto auditado que pode ser uma organização, um programa ou uma atividade. A 
finalidade das auditorias operacionais é adquirir melhorias em relação a este objeto, estabelecendo parâmetros entre meios e fins (BRASIL, 2009).

Para a melhor compreensão das definições acima são apresentados, de maneira sucinta, os conceitos de economia, eficiência, eficácia e efetividade para auditoria operacional de acordo com o Manual de Auditoria Operacional da União (BRASIL, 2009):

\begin{abstract}
a. economia: ou economicidade, consiste na otimização dos resultados, por meio da escolha dos menores custos, mantendo em um nível aceitável as despesas com aquisição e/ou alocação dos recursos humanos, financeiros ou materiais utilizados. Assim, trata da capacidade do gestor em adquirir e administrar de modo adequado os recursos, mantendo os custos baixos;

b. eficiência: trata da otimização dos processos de transformação de insumos em produtos, de maneira a aproveitá-los ao máximo sem redução da qualidade. Mede, portanto, a relação custo-benefício dos atos de gestão;

c. eficácia: é a capacidade de alcance dos objetivos, das metas e das prioridades fixados no planejamento das ações do órgão. Tais objetivos podem ser expressos, tanto em meta de produção (produtos) quanto atendimento (serviços); e

d. efetividade: "trata-se de verificar a ocorrência de mudanças na população-alvo que se poderia razoavelmente atribuir às ações do programa avaliado.
\end{abstract}

Dessa forma, a auditoria operacional ou de desempenho busca avaliar a gestão pública, constituindo-se como um instrumento para melhoria dos programas e sua implementação, tendo como base critérios como economicidade, eficiência, eficácia e efetividade, chamando a atenção dos administradores para os novos tempos, em que se exige da administração pública o alcance de resultados favoráveis em benefício da sociedade, contribuindo também para a melhoria contínua do setor público.

\title{
Lei Complementar $\mathbf{n}^{0}$ 101/ 2000- Lei de Responsabilidade Fiscal
}

Por sua vez, a Lei de Responsabilidade Fiscal, lei n ${ }^{\circ}$ 101/ 2000 (que tem como premissas o planejamento, a transparência e o controle), dispõe em seu artigo. 59, que o Poder Legislativo, diretamente ou com o auxílio do Tribunal de contas, e o sistema de controle interno do Poder Executivo fiscalizará o cumprimento das normas nela estabelecidas, com ênfase no grupo que se refere a:

Limites e condições para realização de operações de crédito e inscrição em Restos a pagar; Atingimento das metas estabelecidas na lei de diretrizes orçamentárias; Medidas adotadas para o retorno da despesa total com pessoal ao respectivo limite, nos termos dos artigos 22 e 23; Providências tomadas, conforme o disposto no art. 31, para recondução dos montantes das dívidas consolidada e mobiliária aos respectivos limites;Destinação de recursos obtidos com a alienação de ativos tendo em vista as restrições constitucionais e as desta lei 
complementar; Cumprimento do limite de gastos totais dos legislativos municipais quando houver.

O controle interno passou a ser visto de forma efetiva e ampla a partir da edição da lei de Responsabilidade Fiscal. Essa lei promulgada em 2000 veio para acabar com a cultura perniciosa até então dominante, cujos resultados apontavam para déficits crônicos; dívidas não pagas; bancos financiando déficit; bancos estaduais falidos. Toda essa cultura resultou em carga tributária elevadíssima para o contribuinte. Tudo isso precisava mudar, dispor de regras de construção de um plano onde a receita supere os gastos.

\section{Caracterização da pesquisa, coleta e análise dos dados}

Trata-se de um estudo descritivo de natureza qualitativa, obtido por meio de pesquisa bibliográfica. Na investigação qualitativa, os dados são coletados no ambiente em que os fatos ocorrem; o pesquisador descreve o fenômeno interagindo com o que o que é pesquisado. A interpretação dos dados ocorre através do enfoque indutivo, com um foco maior no processo do que nos resultados da pesquisa (Cresweel, 2007).

A base principal para a construção do referencial teórico foram os Manuais, livros, catálogos, Teses, dissertações, e monografias, Periódicos nacionais, leis, decretos, manuais, instruções normativas etc. Todos com temática relacionada ao Controle Interno na Administração Pública.

Após a triagem dos conteúdos, começou-se a compreensão analítica, por meio da leitura das obras selecionadas, o que proporcionou a instituição das ideias por ordem de relevância e importância ao tema para alcançar os objetivos esperados .

A pesquisa bibliográfica, portanto, permite um grande acesso às informações, além de possibilitar a empregabilidade de dados dispersos em várias publicações, contribuindo também na produção, ou na definição melhor do leque conceitual que abrange o objeto de estudo proposto neste artigo - Controle Interno (GIL, 1994). 


\section{Considerações Finais}

O controle interno dos municípios, já apreciado na lei n. 4.320/64, recebeu novo enfoque com a exigência constitucional prevista no artigo 31 da Constituição Federal.. Na busca de uma nova estrutura estatal, a Lei de Responsabilidade Fiscal fixou normas de finanças públicas voltadas para a responsabilidade fiscal, a qual pressupõe a ação planejada e transparente, em que se previnem riscos capazes de afetar o equilíbrio das contas públicas, ou seja, essa lei estabelece um novo padrão para governar e promover o conceito de accountability, com foco no desempenho, responsabilização e dever de prestar contas ao cidadão, introduzindo uma nova cultura social e fiscal no País.

Esta nova visão impõe aos municípios a implantação de um Sistema de Controle Interno, intensificando, além do controle da execução orçamentária, a fiscalização contábil, financeira, operacional e patrimonial, bem como a necessidade de se verificar a legalidade dos atos administrativos e o cumprimento dos programas de trabalho. Ou seja, os cidadãos acordaram e agora esperam que os governantes produzam e mostrem os resultados obtidos, para tanto, apresentem uma administração ágil, responsável e eficiente, de forma que qualquer civil possa entender o que está acontecendo e também possa participar da vida do Estado, em um exercício de plena cidadania.

O controle interno vai além da fiscalização e verificação da aplicabilidade das normas e princípios da administração pública. Pode ser considerado um instrumento de gestão essencial para uma administração moderna, transparente e focada na obtenção de resultados, como também um importante meio para combater a corrupção.

Gradativamente, o Controle Interno ganhou importância e destaque com determinações, inclusive de ordem constitucional, que exigem a implantação na Administração Pública, as quais podemos destacar: a Lei no 4320/64, o Decreto-Lei no 200/67, a Constituição Federal de 1988, a Lei $n^{\circ}$ 8.666/1993 - Lei de Licitações e Contratos Administrativos e a Lei Complementar no 101/2000 Lei de Responsabilidade Fiscal.

O município que possuí um Sistema de Controle Interno precisa realizar capacitações nas áreas de controle e em áreas convergentes, entretanto, para assegurar a existência de profissionais capacitados para exercer as atividades da área, priorizando a capacitação para servidores efetivos. 
Para que haja efetividade na realização dos procedimentos e atividades inerentes ao Sistema de Controle Interno é imprescindível que todos os órgãos e unidades que compõe a estrutura administrativa municipal estejam alinhados e envolvidos na busca de melhores resultados.

Tendo em vista o objetivo geral desse trabalho que consiste em evidenciar o papel do Controle Interno como instrumento de gestão na administração pública municipal tomando como base uma pesquisa bibliográfica. $\mathrm{O}$ presente estudo discorreu sobre as legislações pertinentes ao tema, as circunstâncias ou situações consideradas indispensáveis para o adequado exercício das funções e compreensão do sistema de controle interno.

A Administração Pública tem como objetivo atender às demandas emanadas da sociedade por meio da prestação de serviços públicos, tais como saúde, educação, emprego, segurança, moradia, cultura, dentre muitas outras; para tanto, o gestor terá que estruturar e organizar uma série de meios (materiais, tecnológicos, financeiros, humanos etc.). Dessa forma, para que tais demandas sejam atendidas de forma satisfatória, com a devida qualidade dos serviços prestados e efetivo alcance das ações, faz-se necessária a organização de um sistema de controle interno, cuja responsabilidade deve envolver a participação de todos os órgãos e unidades de uma organização.

Por fim, entende-se que as crescentes demandas da sociedade e a limitação dos recursos públicos requerem que todo administrador busque formas de melhor controlar os seus recursos gerenciais para que haja a garantia da prestação dos serviços públicos, que somente será alcançada por meio de uma gestão pública eficaz.

\section{Referências}

ANDRADE, Z.R. O Controle Interno de órgãos Municipais. Florianópolis: tribunal de Contas do Estado de Santa Catarina, 1989.

ARAÚJO, Inaldo da Paixão Santos. Introdução à Auditoria Operacional. $3^{\text {a }}$ edição, Rio de Janeiro. Editora FGV, 2006.

BRASIL. Constituição (1988). Constituição da República federativa do Brasil Brasília: Ed. Do Senado Federal, 1988.

Tribunal de Contas da União. Manual de Auditoria Operacional. 2009. Não publicado. Lei Complementar $n^{\circ} 101$, de 04 de maio de 2000. Estabelece normas de finanças públicas voltadas para a responsabilidade na gestão fiscal e dá outras providências. 
Lei $\mathrm{n}^{\circ} 12.527$ de 18 de novembro de 2011. Regula o acesso à informação previsto no inciso XXXIII do art. $5^{\circ}$, no inciso II do $\S 3^{\circ}$ do art. 37 e no $\S 2^{\circ}$ do art. 216 da Constituição federal; altera a Lei de $\mathrm{n}^{\circ}$ 8.112, de 11 de dezembro de 1990; revoga a Lei $\mathrm{n}^{\circ} 11.111$ de 5 de maio de 2005 , e dispositivos da Lei no 8.159, de 8 de janeiro de 1991 e dá outras providências. Brasília, 1993.

. Lei $\mathrm{n}^{\circ}$ 4.320, de 17 de março de 1964. Estatui Normas Gerais de Direito Financeiro para Elaboração e Controle dos orçamentos e Balanços da União, dos Estados, dos municípios e do Distrito Federal. Brasília, 1964.

. Lei no 8.666 de 21 de junho de 1993. Regulamenta o art. 37, Inciso XXI, da Constituição Federal. Institui normas para Licitações e Contratos da Administração Pública e dá outras providências. Brasília, 1993.

CASTRO, Domingos Poubel. Auditoria e Controle Interno na Administração Pública. 2 Ed. São Paulo. Editora Atlas, 2009.

Domingos Poubel. Auditoria, Contabilidade e Controle Interno no Setor Público. 5 Ed. São Paulo. Editora Atlas, 2013.

CAVALHEIRO, Jader Branco. A Organização do Sistema de Controle Interno Municipal. 4 Ed. Porto Alegre. 2007.

CHAVES, Renato Santos. Auditoria e Controladoria no Setor Público: fortalecimento dos controles internos, com jurisprudência do TCU. Curitiba: Juruá, 2009.

CRESWELL, John W. Projeto de Pesquisa: Métodos Qualitativo, Quantitativo e Misto; tradução Magda Lopes. -3 ed. Porto Alegre: Artmed, 2010.

CRUZ Flávio da \& GLOCK José Osvaldo. O Controle Interno nos Municípios -Orientação para Implantação e Relacionamento com os Tribunais de Contas. São Paulo, Atlas 2003.

DI PIETRO, Maria Sylvia Zanella. Direito Administrativo. 12. Ed. São Paulo: Atlas, 2000.

DI PIETRO, Maria Sylvia Zanella. Direito Administrativo. 18. Ed. São Paulo: Atlas, 2005.

FAYOL, Henry. Administração industrial e geral: previsão, organização, comando, coordenação, controle. 10. Ed. São Paulo: Atlas, 1998.

FERNANDES, Maria Luciene Cartaxo. Sistema de controle interno. Disponível em: <http://citadini.com.br/atuacao/2001/tcepe0011.htm>. Acesso em: 12 jun. 2019.

GATTRINGER, João Luiz. V Ciclo de estudos de controle público da administração municipal. Florianópolis: ACOM, 2006.

GIL AC. Métodos e técnicas de pesquisa social. $4^{\mathrm{a}}$ ed. São Paulo: Ed. Atlas; 1994.

GRANJEIRO, J. Wilson. Administração Pública. Brasília: Vestcon, 2006. 
INTOSAI - Internacional Organizationof Supreme Audit Institutions. Guia para normas de Controle Interno. Trad. Heloísa Garcia Vidal pinto. Revista do Tribunal de Contas do Distrito Federal, Brasília, v. 19, 1993.

MATIAS-PEREIRA, José. Manual de Gestão Pública Conteporânea. 4. Ed. São Paulo: Atlas, 2012.

MEIRELLES, Hely Lopes. Direito Administrativo Brasileiro. 24. Ed. Atualizada por Eurico Andrade Azevedo, Délcio Balestero Aleixo e José Emmanuel Burle Filho. São Paulo: Malheiros, 1999.

PLATERO, Norberto P. Controle e Transparência no Setor Público. Controladoria-Geral da União - CGU in $1^{\text {a }}$ Conferência Nacional sobre Transparência e Controle Social de 18 a 20 de maio de 2012. Disponível no site http://www.consocial.cgu.gov.br. Acesso em: 18 jun. 2019.

SANCHES. Osvaldo Maldonado. Dicionário de Orçamento, Planejamento e Áreas Afins. Brasília: 1997.

SALOMÃO, Luiz. Avaliação de políticas públicas. In: Fiscalização de gastos públicos no Brasil. Brasília: Tribunal de Contas da União, Instituto Serzedello Correa, 1999.

SILVA, José Afonso. Curso de Direito Constitucional Positivo. 22. Ed. São Paulo: Malheiros, 2004. 